\title{
Examination of the frequency of upward and downward fluctuations in the pressure obtained from the cuff pressure-time curve by continuous measurement of endotracheal tube cuff pressure during thyroid surgery: a case series
}

\author{
Koko Adachi ${ }^{*}$, Y Yoshinobu Kameyama and Kohkichi Andoh
}

\begin{abstract}
Background: Few studies examined time-to-time changes of cuff pressure of an endotracheal tube during surgery. We retrospectively analyzed the changes of cuff pressure during thyroid surgery and examined its relationships with postoperative airway complications.

Case presentation: Cuff pressure was initially adjusted at $26 \mathrm{cmH}_{2} \mathrm{O}$ and continuously measured in 61 patients. The cuff pressure-time curve dynamically fluctuated, and exceeded $30 \mathrm{cmH}_{2} \mathrm{O}$ in all patients, whereas decreased to $\leq 20 \mathrm{cmH}_{2} \mathrm{O}$ in 42 (69\%) patients. Ratio of the period with such an increase and decrease of cuff pressure to the total duration of surgery were $40 \%(28-66 \%)$ and $9 \%(0-21 \%)$, respectively (median, interquartile range). No patients showed symptoms of airway stenosis requiring treatment except one who developed recurrent laryngeal nerve palsy. No patients had lower respiratory tract infection.
\end{abstract}

Conclusions: Cuff pressure dynamically fluctuated during thyroid surgery. Preventing an increase as well as decrease of cuff pressure is required.

Keywords: Cuff pressure, Thyroid surgery, Postoperative airway complications

\section{Background}

In recent years, the importance of maintaining optimal endotracheal tube cuff pressure by continuous measurement has been recognized in the field of intensive care [1]. In thyroid surgery, the surgical procedure affects the cuff pressure [2]. Endotracheal tube cuff pressure has been reported to increase, but not decrease, during thyroid surgery [2]. In this study, we showed fluctuations of cuff pressure using the cuff pressure-time curve. We also

\footnotetext{
* Correspondence: ko-ko@med.tohoku.ac.jp

Department of Anesthesiology, Sendai City Hospital, 1-1-1 Asutonagamachi, Taihaku-ku, Sendai 982-8502, Japan
}

Springer Open investigated the frequency of deviation from the optimal cuff pressure and the resulting postoperative airway complications.

\section{Case presentation \\ Methods}

This study was approved by the Ethics Committee of Sendai City Hospital (No. 608). We retrospectively examined cuff pressure which was continuously measured during thyroid surgery at Sendai City Hospital from 2016 to 2019. General anesthesia was induced with propofol $1-2 \mathrm{mg} / \mathrm{kg}$, remifentanil $0.2-0.5 \mu \mathrm{g} / \mathrm{kg} / \mathrm{min}$, and

(c) The Author(s). 2021 Open Access This article is licensed under a Creative Commons Attribution 4.0 International License, which permits use, sharing, adaptation, distribution and reproduction in any medium or format, as long as you give appropriate credit to the original author(s) and the source, provide a link to the Creative Commons licence, and indicate if changes were made. The images or other third party material in this article are included in the article's Creative Commons licence, unless indicated otherwise in a credit line to the material. If material is not included in the article's Creative Commons licence and your intended use is not permitted by statutory regulation or exceeds the permitted use, you will need to obtain permission directly from the copyright holder. To view a copy of this licence, visit http://creativecommons.org/licenses/by/4.0/. 
rocuronium $0.6-0.8 \mathrm{mg} / \mathrm{kg}$ in all cases. After insertion of a spiral tracheal tube (internal diameter $7.0 \mathrm{~mm}$ for female and $8.0 \mathrm{~mm}$ for male patients), general anesthesia was maintained with propofol $4-7 \mathrm{mg} / \mathrm{kg} / \mathrm{h}$, remifentanil $0.2-0.5 \mu \mathrm{g} / \mathrm{kg} / \mathrm{min}$, and a bolus of fentanyl $2-8 \mu \mathrm{g} / \mathrm{kg}$. After adjusting cuff pressure to $26 \mathrm{~cm} \mathrm{H}_{2} \mathrm{O}$ with a pressure gauge following tracheal intubation, it was continuously monitored using a blood pressure monitoring kit connected to the pilot balloon of a tracheal tube. Tracheal tube was removed after administration of sugammadex $200 \mathrm{mg}$ at the discretion of the anesthesiologist on completion of surgery. Cuff pressure-time curve was made based on the recorded data every minute. The duration of cuff pressure $\geq 30 \mathrm{cmH}_{2} \mathrm{O}$ or $\leq 20 \mathrm{cmH}_{2} \mathrm{O}$ was measured and expressed as the ratio to the total duration of surgery.

Postoperative airway complications included airway stenosis symptoms and airway infection [1]. Airway stenosis symptoms were defined as subjective findings, such as difficulty in breathing, and objective findings, such as stenotic sounds and tracheal edema confirmed using bronchoscopy. Respiratory tract infections were defined as lower respiratory tract infections requiring postoperative treatment.

Numerical values are presented as median (25\% and $75 \%$ interquartile range). Statistical analysis was performed by Wilcoxon's sum test using JMP ${ }^{\bullet}$ Pro 16 (SAS Institute Inc., Cary NC, USA) and $P<0.05$ was regarded as significant.

\section{Results}

Of a total of 884 cases, cuff pressure was measured in 61 (16 male and 45 female) cases aged 48 (37-62) years undergoing thyroid surgery for cancer, Graves' disease, and adenoma ( $n=31,19$, and 11, respectively). The cuff pressure fluctuated during surgery (Fig. 1). It increased $\geq$ $30 \mathrm{~cm} \mathrm{H}_{2} \mathrm{O}$ in all cases and decreased $\leq 20 \mathrm{cmH}_{2} \mathrm{O}$ in 42 (69\%) patients. Duration of such an increase and decrease of cuff pressure was 40\% (28-66\%) and 9\% (0$32 \%)$ of the operation time, respectively. There were five

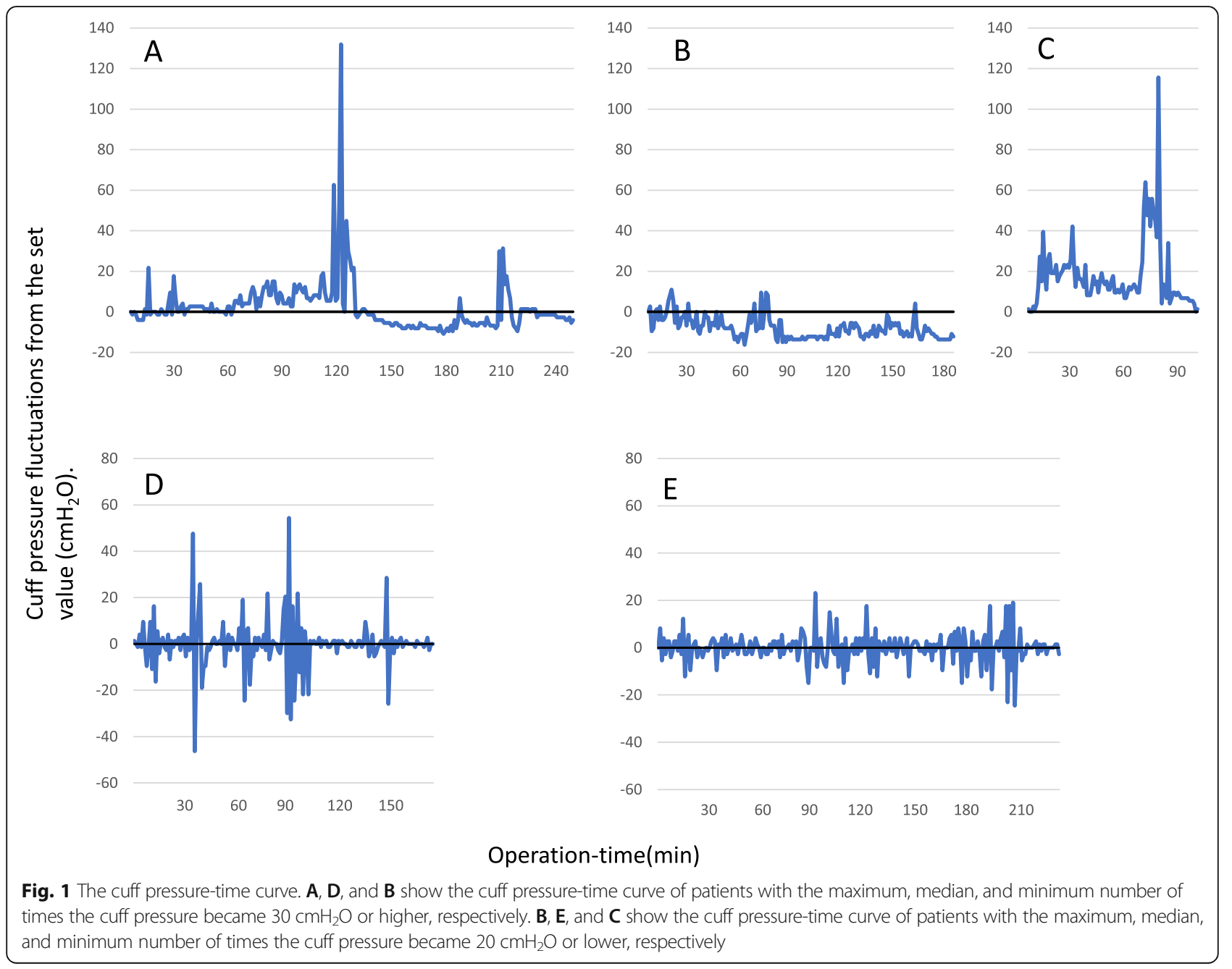


Table 1 The relationship between the presence or absence of post-operative airway stenosis symptoms and cuff pressure

\begin{tabular}{lll}
\hline & $\begin{array}{l}\text { The number of times the cuff pressure } \\
\text { became } \mathbf{3 0}{\mathbf{~} \mathbf{m ~ H}_{\mathbf{2}} \mathbf{O} \text { or higher (times) }}\end{array}$ & $\begin{array}{l}\text { The ratio to operation time the cuff pressure } \\
\text { became } \mathbf{3 0} \mathbf{c m H}_{\mathbf{2}} \mathbf{O} \text { or higher (\%) }\end{array}$ \\
\hline With airway stenosis symptoms $(n=5)$ & $55(32-92)$ & $40(16-80)$ \\
Without airway stenosis symptoms $(n=56)$ & $48(29-68)$ & $40(28-66)$ \\
$P$ value & 0.7523 & 0.9057 \\
\hline
\end{tabular}

cases of postoperative airway stenosis symptoms, four of which showed difficulty in breathing without findings of airway obstruction. Upon follow-up, the symptoms disappeared. In one case of stenotic sounds, bilateral recurrent laryngeal nerve palsy was confirmed by flexible fiber-optic laryngoscopy after reintubation and extubation. Table 1 shows the relationship between the presence or absence of postoperative airway stenosis symptoms and cuff pressure. There were no cases of lower respiratory tract infection requiring treatment.

\section{Discussion}

In thyroid surgery, cuff pressure is affected by the surgical procedure [2]. There are reports of increased cuff pressure during thyroid surgery [2]; however, to our best knowledge, there is no report stating that the cuff pressure fluctuates upward and downward like a sawtooth wave. This shows that cuff pressure adjustment is necessary to maintain a constant cuff pressure. The use of an automatic cuff pressure regulator that responds to sudden cuff pressure fluctuations can be considered [3].

A cuff pressure of $30 \mathrm{cmH}_{2} \mathrm{O}$ or higher that may block blood flow in the tracheal mucosa [1, 4] was observed in all cases. The optimal cuff pressure exceeded approximately $40 \%$ of the operation time. However, in four of the five cases showing postoperative complications, the difficulty of breathing disappeared during follow-up. In one case of stenotic sound, bilateral recurrent laryngeal nerve palsy was noted postoperatively. There was no association between these symptoms and a cuff pressure of $\geq 30 \mathrm{cmH}_{2} \mathrm{O}$ (Table 1). There is no report on the duration of the increase in cuff pressure to cause tracheal mucosa ischemia. In this study, the cuff pressure fluctuated upward and downward, similar to the sawtooth wave, and the presence of ischemia release time may be beneficial.

Cuff pressure decreased $\leq 20 \mathrm{cmH}_{2} \mathrm{O}$ in 42 (69\%) patients. This is the first report to show that cuff pressure not only increased but decreased, although there were no cases of respiratory tract infections requiring postoperative treatment. It has been reported that continuous cuff pressure adjustment reduces ventilator-associated pneumonia (VAP) in the intensive care unit [1]. In the future, it will be necessary to consider the relationship between maintaining cuff pressure during surgery and VAP.
The limitation of this study, there were few cases of airway stenosis symptoms, and multivariate analysis could not be performed on the factors that caused airway stenosis. The cause of airway stenosis is thought to be not only the obstruction of blood flow in the tracheal mucosa due to increased cuff pressure, but also the original condition of the trachea and surgical invasion. In the future, the relationship with these factors should be examined by increasing the number of cases. Another limitation is that the cuff pressure was recorded every one minute, which was assumed to be unchanged for one minute and actual time course was not known. However, it was useful to show that the cuff pressures frequently upward and downward fluctuations from the optimal cuff pressure.

\section{Conclusions}

Cuff pressure increased $\geq 30 \mathrm{cmH}_{2} \mathrm{O}$ in all patients and decreased $\leq 20 \mathrm{cmH}_{2} \mathrm{O}$ in $42(69 \%)$ patients, for $40 \%$ $(28-66 \%)$ and $9 \%(0-32)$ of the total duration of thyroid surgery. Prevention of an increase as well as decrease of cuff pressure would be required. Although this study was not related to postoperative complications, it is necessary to consider measures against not only an increase in cuff pressure, but also a decrease in cuff pressure.

Abbreviation

VAP: Ventilator-associated pneumonia

\section{Acknowledgements}

We would like to thank Editage (www.editage.com) for English language editing.

Authors' contributions

KA designed the study, wrote most of the manuscript, and performed analysis and interpretation of the data. YK and KA contributed to data collection and interpretation of data. All authors were involved in drafting or revision of the manuscript. All authors have read and approved the final manuscript.

\section{Funding}

None

\section{Availability of data and materials}

The datasets used and/or analyzed during the current study are available from the corresponding author upon reasonable request. 


\section{Declarations}

\section{Ethics approval and consent to participate}

This study was approved by the Ethics Committee at Sendai City hospital

(Sendai, Miyagi, Japan, approval number: 608).

\section{Consent for publication}

This study used the opt-out method to obtain consent for publication and participation.

\section{Competing interests}

The authors declare that they have no competing interests.

Received: 1 June 2021 Revised: 2 August 2021

Accepted: 2 August 2021 Published online: 19 August 2021

\section{References}

1. Kumar CM, Seet E, Van Zundert TCRV. Measuring endotracheal tube intracuff pressure: no room for complacency. J Clin Monit Comput. 2021; 35(1):3-10. https://doi.org/10.1007/s10877-020-00501-2.

2. Ryu J-H, Han S-S, Do S-H, Lee J-M, Lee S-C, Choi E-S. Effect of adjusted cuff pressure of endotracheal tube during thyroidectomy on postoperative airway complications: prospective, randomized, and controlled trial. World J Surg. 2013;37:786-91.

3. Michikoshi J, Matsumoto S, Miyawaki H, Niu H, Seo K, Yamamoto M, et al. Performance comparison of a new automated cuff pressure controller with currently available devices in both basic research and clinical settings. J Intensive Care. 2016;4(1):4. https://doi.org/10.1186/s40560-016-0126-7.

4. Seegobin RD, van Hasselt GL. Endotracheal cuff pressure and tracheal mucosal blood flow: endoscopic study of effects of four large volume cuffs. Br Med J. 1984;288(6422):965-8. https://doi.org/10.1136/bmj.288.6422.965.

\section{Publisher's Note}

Springer Nature remains neutral with regard to jurisdictional claims in published maps and institutional affiliations.

\section{Submit your manuscript to a SpringerOpen ${ }^{\odot}$ journal and benefit from:}

- Convenient online submission

- Rigorous peer review

- Open access: articles freely available online

- High visibility within the field

- Retaining the copyright to your article 